\title{
The impact of HIV/AIDS stigma on HIV counseling and testing in a high HIV prevalence population in Uganda
}

\author{
*Ayiga $\mathrm{N}^{1}$, Nambooze $\mathrm{H}^{2}$, Nalugo $\mathrm{S}^{2}$, Kaye $\mathrm{D}^{2}$, Katamba $\mathrm{A}^{2}$
}

\author{
1. Population Training and Research Unit, Mafikeng Campus, Private Bag X2046, North West University, \\ Mmabatho 2735 \\ 2. College of Health Sciences, Makerere University, P.O Box 7072, Kampala, Uganda
}

\begin{abstract}
Background: Despite its importance in HIV/AIDS prevention and treatment, HIV/AIDS Counseling and Testing (HCT) is low in sub-Saharan Africa, where the disease continues to be a serious public health problem. This has in part been attributed to HIV/AIDS related stigma.

Objective: To assess the level of HIV/AIDS related stigma and its impact on uptake of HCT in a high HIV prevalence population in Uganda.

Methods: The paper used cross-sectional data on 135 men and 185 women in reproductive ages. Data were analyzed using the Pearson's chi-square statistic and the random intercept binary logistic regression model to identify significant predictors of uptake of HCT.

Results: The result shows that only $18.4 \%$ of the respondents, most of them men expressed highly stigmatizing attitudes against PLHA and 59\%, men and women alike, received HCT. Uptake of HCT was higher among men $(\mathrm{OR}=1.89, \mathrm{p}<0.01)$ and women $(\mathrm{OR}=4.48, \mathrm{p}<0.001)$ who expressed least stigmatizing attitudes. Secondary/higher education, work in the informal sector and being ever married were significant predictors of uptake of HCT. Compared to men, women aged 2534, 35+ and with one sexual partner were more likely to have received HCT.

Conclusions: The low level of stigma, older age, higher level of education, being ever married and monogamous sexual relationships are significant predictors of increased uptake of HCT.

Key words: HIV counseling and Testing, Stigma, Uganda

African Health Sciences 2013; 13(2): 278 - 286 http:/ /dx.doi.org/10.4314/ahs.v13i2.12
\end{abstract}

\section{Introduction}

Nearly three decades since its discovery, HIV/AIDS continues to be a serious health problem in subSaharan Africa where 22.4 million people were living with HIV/AIDS and 1.4 million people died of the disease in $2008^{1}$. Uganda with HIV/AIDS prevalence rate of $6.4 \%$ ( $7.5 \%$ of females and $5.0 \%$ of males) is one of the sub-Saharan African countries most affected by the disease. Despite this high prevalence, only $11 \%$ of men and $13 \%$ of women in Uganda have tested for HIV and received their test results ${ }^{2}$, which has been partly attributed to HIV/AIDS stigma ${ }^{3}$.

HIV/AIDS is a stigmatized disease because it discredits, degrades and reduces the worthiness

*Corresponding author:
Natal Ayiga
Population Training and Research Unit
North West University, Mafikeng Campus
Private Bag X2046, Mmabatho 2735
South Africa
Email: Natal.Ayiga@nwu.ac.za ;
nayiga1962@gmail.com

of people who have it in the eyes of society ${ }^{4}$. HIV/ AIDS stigma has been categorized into felt and enacted stigma. Felt stigma includes self isolation, blame, shame, guilt and denial of HIV/AIDS positive status by people who are infected and affected by the disease ${ }^{5}$.

Enacted stigma includes ostracism, ridicule, neglect of health care and violence against PLHA perpetuated by family, peers, health personnel and other community members ${ }^{6}$. A previous study found the above forms of HIV/AIDS stigma to be common in Uganda ${ }^{3}$.

It is now recognized that HIV/AIDS stigma can be a barrier to seeking HIV/AIDS related services including HIV Counseling and Testing (HCT) ${ }^{7,8}$. This is because HIV/AIDS stigma contributes to secrecy and denial of the infection by infected people ${ }^{8}$. Fear of marital disruption ${ }^{9}$, shame and embarrassment among older people ${ }^{10}$, regular use of condoms; having multiple concurrent sexual partners ${ }^{11}$, and inadequate and inconvenient HCT services have also contributed to the low uptake of $\mathrm{HCT}^{12}$. Previous studies cited some of the above reasons for the low uptake of HCT in Uganda ${ }^{3,9}$. 
Despite nearly $83 \%$ of the district's population having access to HIV/AIDS services by $2008^{10}$, Central Uganda where Rakai district is located, with $8.5 \%$ had the highest HIV/AIDS prevalence rate in Uganda ${ }^{11}$. Stigma reduction and HCT services were among the first and now widely available HIV/AIDS services in Uganda in general and Rakai district in particular because of the important roles they are known to play in HIV prevention and AIDS treatment ${ }^{12}$. We therefore hypothesize a low HIV/AIDS stigma and high uptake of HCT in Rakai district.

The objectives of the study were to assess the level of HIV/AIDS stigma and its impact on uptake of HCT.

\section{Methods}

\section{Study population}

The paper used cross-sectional data collected in Kyotera and Kakuuto counties in Rakai district in 2006. Rakai is in Central Uganda and is the district where the first HIV/AIDS case in Uganda was identified in 1982.

The multi-stage sampling design was used to select 135 men and 185 women from Kyotera and Kakuuto, which were selected out of 4 counties using simple random sampling in the first stage. Kalisizo and Lwankoni, and Kasasa and Kifamba sub-counties were selected from Kyotera and Kakuuto counties respectively using simple random sampling in the second stage. From each of the selected sub-counties, 4 villages were selected using simple random sampling method bringing the total number of villages included in the study to 16 . In each village, all households were listed bringing the total number of households to 1,415. Out of the listed households, 10 households were selected in each village for interview using systematic sampling bringing the total number of selected households to 160. All men aged 15-54 and all women aged 1549 in selected households were interviewed bringing the total number of successful interviews to 320 . Men aged 15-54 and women aged 15-49 were selected for the study because these are the ages most at risk to HIV/AIDS.

Data on socio-demographic, sexual and HCT characteristics and stigmatizing attitudes of respondents were collected by using a structured questionnaire. The statements used to assess stigma in this study were adopted from previous studies ${ }^{13}$, ${ }^{14}$ and pre-tested in a village not included in the sample. The questionnaire was first translated from
English to Luganda and then back to English to ensure that the meanings of the translated questions remain consistent.

\section{Ethical Issues}

Ethical approval was obtained from the Institute of Statistics and Applied Economics Research Committee and later from the Uganda National Council of Science and Technology. Administrative approval was obtained from Rakai District HIV/ AIDS Coordinator (DAC) and District Chief Administrative Officer (CAO) who are responsible for HIV/AIDS activities in the district. Informed consent was obtained from eligible household members who voluntarily accepted to participate in the study. Confidentiality and anonymity of the identity of respondents was ensured by not including their names on the questionnaire.

\section{Measures}

The dependent variable used in this analysis is uptake of HCT, which is taking HCT and receiving the test results. The main independent variable is level of stigma, which was derived from 7 positively constructed stigmatizing attitude statements including "would not blame self if infected with HIV/AIDS"; "would be friends with other people if infected with HIV/AIDS"; "other people would be friends with you if you were infected with HIV/AIDS"; "HIV/ AIDS infected people should not be ashamed of their status"; "would care for a HIV/AIDS infected household member"; "would allow a HIV/AIDS infected teacher to continue teaching"; and "would allow ones child to play with a child with HIV/ AIDS".

The 7 stigma attitude statements were tested for internal consistency and validity by using the cronbach's alfa and the results were 0.68 and 0.69 for un-standardized and standardized statements respectively. The cronbach's alfa ranged from 0.56 to 0.72 even with deletion, indicating that the attitude statements were internally consistent and reliable. A composite stigma variable with two categories namely "highly stigmatizing attitudes" (disagreed with attitude statements) and "least stigmatizing attitudes" (agreed with attitude statements) was computed using the compute option in SPSS. The control measures were socioeconomic characteristics including age of respondents, level of education, marital status and occupational groups. Sexual characteristics included were sexual activity status, ever use of condoms and number of sexual partners at 
the time of the study. More than one sexual partner at the time of the study was regarded having concurrent sexual partnership. Also included in the analyses were awareness of HCT services and willingness to receive HCT in future.

\section{Data analyses}

Data analyses were done in three stages by use of SPSS. In the first stage we described respondents by the explanatory variables which included the composite stigma variable, socio-demographic, sexual, and HCT characteristics. At the second stage we tested the impact of the explanatory variables on uptake of HCT using the chi-square statistic with the level of significance set at $\mathrm{p}<0.05$. Two models disaggregated by sex were performed at the third stage. Model I examined the gross effect of stigma on uptake of HCT and Model II examined the net effect of stigma on uptake of HCT after controlling for the effects of other explanatory variables simultaneously using the random intercept logistic regression model. In this model, county was included as a random variable and uptake of HCT was the dependent variable, which was coded " 1 " if a respondent received HCT and "O" if otherwise ${ }^{15}$.

Only variables which were significantly associated with uptake of HCT at $\mathrm{p}<0.05$ at the bivariate analysis were included in Model II. Measures of goodness of fit were performed for each model and the result showed a good fit with $\mathrm{p}<0.0001$.

\section{Results}

\section{Characteristics of study sample}

Table 1 shows that $42.2 \%$ of the respondents were males and $57.8 \%$ were females. The mean age was 29.2 years for men and 27.6 years for women and most men and women were younger than 35 years. Half of the $(50.6 \%)$, men and women had secondary or higher education. Nearly $72 \%$ were ever married and only $28 \%$ were never married. About $56 \%$ of the respondents worked in the informal sector and $44 \%$ worked in the formal sector. The majority, $92 \%$, males and females alike were sexually active; $75 \%$ had only one sexually partner; $13 \%$, mostly men, had multiple sexual partners concurrently; and nearly $12 \%$ had no sexual partner. The majority of the respondents $(60.3 \%)$, most of them men $(71.9 \%)$ have ever used condoms. Awareness of HCT was nearly universal and the majority $(88.1 \%)$ of men and women $(76.8 \%)$ were willing to receive HCT in future. In contrast, only $58.9 \%$ of the men and $59.3 \%$ of the women received HCT.

Table 1: Socio-demographic characteristics of the study sample by gender

\begin{tabular}{lcccccc}
\hline Characteristics & Males & \multicolumn{3}{l}{ Females } & \multicolumn{2}{c}{ Total } \\
\cline { 2 - 8 } & \% & $\mathbf{n}$ & $\%$ & $\mathbf{n}$ & $\mathbf{\%}$ & $\mathbf{n}$ \\
\hline Age & 54.1 & $(73)$ & 36.8 & $(68)$ & 44.1 & $(141)$ \\
$15-24$ & 30.4 & $(41)$ & 44.9 & $(83)$ & 38.8 & $(124)$ \\
$25-34$ & 15.6 & $(21)$ & 18.9 & $(35)$ & 17.1 & $(55)$ \\
$35+$ & 29.2 & $135)$ & 27.6 & $(185)$ & 28.6 & $(320)$ \\
Mean age & & & & & & \\
County & 51.1 & $(69)$ & 49.2 & $(91)$ & 50.0 & $(160)$ \\
Kakuuto & 48.9 & $(66)$ & 50.8 & $(94)$ & 50.0 & $(160)$ \\
Kyotera & & & & & & \\
Level of education & 48.1 & $(65)$ & 50.3 & $(93)$ & 49.4 & $(158)$ \\
No/ primary & 51.9 & $(70)$ & 49.7 & $(92)$ & 50.6 & $(162)$ \\
Secondary/higher & & & & & & \\
Marital status & 34.1 & $(46)$ & 23.8 & $(44)$ & 28.1 & $(90)$ \\
Never married & 65.9 & $(89)$ & 76.2 & $(141)$ & 71.9 & $(230)$ \\
$\begin{array}{l}\text { Ever married } \\
\text { Occupation }\end{array}$ & & & & & & \\
Formal sector & 51.1 & $(69)$ & 38.4 & $(71)$ & 43.8 & $(140)$ \\
Informal sector & 48.9 & $(66)$ & 61.6 & $(114)$ & 56.3 & $(180)$ \\
Current sexual activity status & & & & & & \\
Sexually active & 91.9 & $(124)$ & 91.9 & $(170)$ & 91.9 & $(294)$ \\
Not sexually active & 8.1 & $(11)$ & 8.1 & $(15)$ & 8.1 & $(26)$ \\
\hline
\end{tabular}




\begin{tabular}{|c|c|c|c|c|c|c|}
\hline \multirow[t]{2}{*}{ Characteristics } & \multicolumn{2}{|c|}{ Males } & \multicolumn{2}{|c|}{ Females } & \multicolumn{2}{|c|}{ Total } \\
\hline & $\%$ & $\mathbf{n}$ & $\%$ & $\mathrm{n}$ & $\%$ & $\mathrm{n}$ \\
\hline \multicolumn{7}{|c|}{ Number of sexual partners } \\
\hline Currently none & 12.6 & (17) & 11.4 & $(21)$ & 11.9 & $(36)$ \\
\hline Currently one & 65.2 & (88) & 82.2 & $(152)$ & 75.0 & $(240)$ \\
\hline Multiple concurrent & 22.2 & $(30)$ & 6.5 & $(12)$ & 13.1 & $(42)$ \\
\hline \multicolumn{7}{|l|}{ Ever used a condom } \\
\hline Yes & 71.9 & (97) & 51.9 & (96) & 60.3 & (193) \\
\hline No & 28.1 & $(38)$ & 48.1 & (89) & 39.7 & (127) \\
\hline \multicolumn{7}{|c|}{ Willingness to receive HCT in future } \\
\hline Yes & \multicolumn{2}{|c|}{88.1 (119) } & \multicolumn{2}{|c|}{76.8 (142) } & 81.6 & $(261)$ \\
\hline No & \multicolumn{2}{|c|}{$11.9(16)$} & \multicolumn{2}{|c|}{$23.2(43)$} & 18.4 & $(59)$ \\
\hline \multicolumn{7}{|l|}{ Ever heard of HCT } \\
\hline Yes & \multicolumn{2}{|c|}{$96.3(130)$} & 98.4 & $(182)$ & 97.5 & $(312)$ \\
\hline No & 3.7 & $(5)$ & 1.6 & (3) & 2.5 & $(8)$ \\
\hline \multicolumn{7}{|c|}{ Ever taken and received HCT results } \\
\hline Yes & \multicolumn{2}{|l|}{58.9} & \multirow{2}{*}{\multicolumn{2}{|c|}{$\begin{array}{l}59.3 \\
41.7\end{array}$}} & 59.1 & $(189)$ \\
\hline No & 41.1 & $(55)$ & & & 40.9 & (131) \\
\hline Total & \multicolumn{2}{|c|}{100.0} & \multicolumn{2}{|c|}{100.0} & \multicolumn{2}{|c|}{$100.0(320)$} \\
\hline
\end{tabular}

Assessment of the level of stigma

Table 2 presents respondents by stigmatizing attitudes showing that $81.6 \%$ expressed least stigmatizing attitudes and only $18.4 \%, 12.2 \%$ of men and $6.2 \%$ of women, expressed highly stigmatizing attitudes. Differentials by gender show that more men than women expressed highly stigmatizing attitudes and the level of stigmatizing attitudes were significantly associated with gender $(\mathrm{p}<0.0001)$.
Impact of stigma on uptake of HCT

The impact of stigma on uptake of HCT is presented in table 3 showing that the majority of men $(64.6 \%)$ and women $(61.8 \%)$ who expressed least stigmatizing attitudes received HCT. Only 46.2\% of men and $35 \%$ of women who expressed highly stigmatizing attitudes received HCT and the level of stigma was significantly associated with uptake of HCT at $\mathrm{p}<0.05$ for both men and women.

Table 2: Respondents distribution by levels of stigma and gender

\begin{tabular}{|c|c|c|c|c|}
\hline \multirow[t]{2}{*}{ Stigmatizing attitudes } & Men & Women & \multirow{2}{*}{$\mathbf{X}_{2}$} & \multirow[t]{2}{*}{ Total $\%$} \\
\hline & $\% \quad \mathrm{n}$ & $\% \quad \mathrm{n}$ & & \\
\hline \multicolumn{5}{|l|}{ Composite stigma index } \\
\hline Highly stigmatizing attitudes & $28.9(39)$ & $10.9(20)$ & $16.96^{* * * *}$ & $18.4(59)$ \\
\hline Least stigmatizing attitude & $71.1(96)$ & $89.2(165)$ & & $81.6(261)$ \\
\hline Total & $100.0(135)$ & $100.0(185)$ & & $100.0(320)$ \\
\hline
\end{tabular}

Level of significance $=* * * *<0.0001$

Table 3: Differentials in uptake of HCT by stigma and gender

\begin{tabular}{|c|c|c|c|c|c|c|c|c|c|c|}
\hline \multirow[t]{3}{*}{ Indicators of stigma } & \multicolumn{4}{|c|}{ Males } & \multirow[t]{3}{*}{$\mathbf{X}_{2}$} & \multicolumn{4}{|c|}{ Females } & \multirow[t]{3}{*}{$\mathbf{X}_{2}$} \\
\hline & \multicolumn{2}{|c|}{$\begin{array}{l}\text { Received } \\
\text { HCT }\end{array}$} & \multicolumn{2}{|c|}{$\begin{array}{l}\text { Did not receive } \\
\text { HCT }\end{array}$} & & \multicolumn{2}{|c|}{$\begin{array}{l}\text { Received } \\
\text { HCT }\end{array}$} & \multicolumn{2}{|c|}{$\begin{array}{l}\text { Did not receive } \\
\text { HCT }\end{array}$} & \\
\hline & $\%$ & $\mathrm{n}$ & $\%$ & $\mathrm{n}$ & & $\%$ & $\mathrm{n}$ & $\%$ & $\mathrm{n}$ & \\
\hline \multicolumn{11}{|l|}{$\begin{array}{l}\text { Composite index } \\
\text { of stigma }\end{array}$} \\
\hline Highly stigmatizing & 46.2 & (18) & 53.8 & (21) & $3.91 *$ & & (7) & 65.0 & (13) & $5.30^{*}$ \\
\hline Least stigmatizing & 64.6 & $(62)$ & 35.8 & (29) & & & (109) & 38.2 & (63) & \\
\hline Total & 59.3 & (80) & 40.7 & (55) & & & (109) & 41.1 & (76) & \\
\hline
\end{tabular}

Level of significance $*<0.05 ; * *<0.01 ; * * *<0.001 ; * * * *<0.0001$ 
Impact of socio-demographic, sexual and HCT characteristics on uptake of HCT

Table 4 shows that uptake of HCT decreased with age among men with $71 \%$ of men aged $15-24$ years and only $28 \%$ of men aged 35 or more years reporting that they received HCT. Among women, uptake of HCT increased with age. About $77 \%$ of women aged 35 or more years and $40 \%$ of women aged 15-24 years received HCT. Uptake of HCT also increased with the level of education from $43.1 \%$ and $47.3 \%$ among men and women with no/ primary education to $74 \%$ and $71 \%$ among men and women with secondary/higher education respectively. Compared to the formal sector, the majority of men and women working in the informal sector received HCT. The majority of ever married men and women; sexually active men and women; men and women who ever used condoms; and had one sexual partner received HCT. Table 4 also shows that nearly $60 \%$ of men and $63.4 \%$ of women, who were willing to receive HCT in future and the majority of men $(61 \%)$ and women $(60 \%)$ who were aware of HCT, previously received the service. The level of education, occupation, marital status and current number of sexual partners were significantly associated with uptake of HCT for both men and women. Conversely, current sexual activity status, ever use of condoms and willingness to receive HCT in future were significantly associated with uptake of HCT for only women.

Table 4: Differentials in uptake of HCT by socio-demographic, sexual and HCT characteristics by sex

\begin{tabular}{|c|c|c|c|c|c|c|}
\hline \multirow[t]{3}{*}{ Characteristics } & \multicolumn{2}{|c|}{ Males } & \multicolumn{3}{|c|}{$\mathbf{X}_{2} \quad$ Females } & \multirow[t]{3}{*}{$\mathrm{X}_{2}$} \\
\hline & \multicolumn{2}{|c|}{ Taken HCT } & & Taken HCT & No HCT & \\
\hline & $\% \quad \mathrm{n}$ & $\%$ & & $\begin{array}{ll}\% & \mathrm{n}\end{array}$ & $\begin{array}{ll}\% & \mathrm{n}\end{array}$ & \\
\hline \multicolumn{7}{|l|}{ Age } \\
\hline $15-24$ & $71.2(52)$ & $28.8(21)$ & \multirow[t]{3}{*}{$10.10^{* * *}$} & $40.3(27)$ & $59.7 \quad(40)$ & \multirow[t]{3}{*}{$16.25^{* * * *}$} \\
\hline 25-34 & $48.8(20)$ & $61.2(21)$ & & $66.3(55)$ & $33.7 \quad(28)$ & \\
\hline $35+$ & $28.1(8)$ & $61.9(13)$ & & $77.1(27)$ & $22.9 \quad(8)$ & \\
\hline \multicolumn{7}{|l|}{ County } \\
\hline Kakuuto & $58.0(40)$ & $42.0(29)$ & \multirow[t]{2}{*}{0.09} & $62.6 \quad(57)$ & $37.4(34)$ & \multirow[t]{2}{*}{1.02} \\
\hline Kyotera & $60.0(40)$ & $39.4(26)$ & & $55.3 \quad(52)$ & $44.7(42)$ & \\
\hline \multicolumn{7}{|l|}{ Level of education } \\
\hline No/primary & $43.1(28)$ & $56.9(37)$ & \multirow[t]{3}{*}{$13.59 * * * *$} & $47.3(44)$ & $52.7(49)$ & $10.41 * * * *$ \\
\hline Secondary/higher & $74.3(52)$ & $25.7(18)$ & & $70.7(65)$ & $29.3(27)$ & \\
\hline Occupation & & & & & & \\
\hline Formerly employed & $43.5(30)$ & $56.5(39)$ & $14.55^{* * * *}$ & $31.0(22)$ & $69.0(49)$ & $37.14 * * * *$ \\
\hline Informally employed & $75.8(50)$ & $24.2(16)$ & & $76.3(87)$ & $23.7(27)$ & \\
\hline Marital status & & & & & & \\
\hline Never married & $45.7(21)$ & $54.3(25)$ & $5.35^{* *}$ & $40.9(18)$ & $59.1(26)$ & $7.74 * * *$ \\
\hline Ever married & $66.3(59)$ & $33.7(30)$ & & $64.5(91)$ & $35.5(50)$ & \\
\hline Current sexual activ & status & & & & & \\
\hline Sexually active & $60.5(75)$ & $39.5(49)$ & 0.95 & $61.8(105)$ & $38.2(65)$ & $7.02 * *$ \\
\hline Not sexually active & $45.5(5)$ & $54.5(6)$ & & $26.7(4)$ & $73.3(11)$ & \\
\hline Ever used a condom & & & & & & \\
\hline Yes & $61.9(60)$ & $38.1(37)$ & 0.96 & $68.8(66)$ & $31.2(30)$ & $7.97 * *$ \\
\hline No & $52.6(20)$ & $47.4(18)$ & & $48.3(43)$ & $51.7(46)$ & \\
\hline Number of sexual $p$ & tners & & & & & \\
\hline Currently none & $47.1(8)$ & $52.9(9)$ & $11.08^{* * *}$ & $23.8(5)$ & $46.2(16)$ & $14.59 * * *$ \\
\hline Currently one & $69.3(61)$ & $30.7(27)$ & & $65.1(99)$ & $34.9(53)$ & \\
\hline Multiple & $36.7(11)$ & $63.3(19)$ & & $41.7(5)$ & $58.3(7)$ & \\
\hline Willingness to take & $T$ in future & & & & & \\
\hline Yes & $59.7(71)$ & $40.3(48)$ & 2.5 & $63.4(90)$ & $43.6(52)$ & \\
\hline No & $56.3(9)$ & $43.7(7)$ & & $44.2(19)$ & $54.8(24)$ & $6.82^{*}$ \\
\hline Ever heard of HCT & & & & & & \\
\hline Yes & $60.8(79)$ & $39(51)$ & 3.3 & $59.9(109)$ & $40.1(73)$ & 4.37 \\
\hline No & $20.0(1)$ & 80.0 (4) & & $0.0(0)$ & $100.0(3)$ & \\
\hline Total & $59.3(80)$ & $40.7(55)$ & & $58.9(109)$ & $41.1(76)$ & \\
\hline
\end{tabular}

Level of significance $*<0.05 ; * *<0.01 ; * * *<0.001 ; * * * *<0.0001$ 


\section{Predictors of HCT}

The gross and net effects of stigma on uptake of HCT are presented in Models I and II (table 5). In both models highly stigmatizing attitude was the reference category. Model I shows that men and women who had least stigmatizing attitude were 2.13 $(\mathrm{p}<0.01)$ and $3.01(\mathrm{p}<0.01)$ times respectively significantly more likely to have received HCT. The net effect model shows that the Odds of receiving HCT reduced to $1.89(\mathrm{p}<0.05)$ times for men and increased to $4.48(\mathrm{p}<0.01)$ times for women who had least stigmatizing attitudes after controlling for all other variables simultaneously. Having least stigmatizing attitudes remained a significant predictor of uptake of HCT. Regarding the control variables, men who had secondary/higher education $(\mathrm{OR}=3.80, \mathrm{p}<0.001)$; worked in the informal sector $(\mathrm{OR}=5.29, \mathrm{p}<0.001)$; and were ever married $(\mathrm{OR}=7.14, \mathrm{p}<0.001)$ were significantly more likely to have received HCT. Conversely, men who were 15-24 years $(\mathrm{OR}=0.14, \mathrm{p}<0.001)$; and have never used condoms (OR0.84, $\mathrm{p}<0.01)$ were significantly less likely to have received HCT. Additionally, women were significantly more likely to have received HCT if they were $25-34(\mathrm{OR}=5.48, \mathrm{p}<0.001)$ and 35 or more years old $(\mathrm{OR}=3.53, \mathrm{p}<0.01)$; had secondary/ higher education $(\mathrm{OR}=4.56, \mathrm{p}<0.0001)$; worked in the informal sector $(\mathrm{OR}=8.07, \mathrm{p}<0.0001)$; and were ever married $(\mathrm{OR}=2.10, \mathrm{p}<0.01)$. Women who had only one sexual partner and were willing to receive HCT in future were $1.60(\mathrm{p}<0.05)$ and $1.28(\mathrm{p}<0.01)$ times respectively significantly more likely to have received HCT.

Test for the random effect associated with counties as a cluster variable in table 5 show that the random intercept is -11.0 for men and -9.1 for women; and the residual variance is 0.001 for both men and women. The inter cluster correlation (ICC) is less than $1 \%$; and the likelihood ratio test $\mathrm{p}>0.05$ for both men and women and therefore not significant, suggesting that counties did not impact on uptake of HCT.

Table 5: Logistic regression coefficients of the impact of stigma on socio-demographic and sexual characteristics of respondents by sex

\begin{tabular}{|c|c|c|c|c|c|c|c|}
\hline \multirow[t]{3}{*}{ Predictors } & \multicolumn{4}{|c|}{ Men } & \multicolumn{3}{|c|}{ Women } \\
\hline & \multicolumn{2}{|c|}{$\begin{array}{l}\text { Model I } \\
\text { Net effects }\end{array}$} & \multicolumn{2}{|c|}{$\begin{array}{l}\text { Model II } \\
\text { Gross Effects }\end{array}$} & \multicolumn{2}{|c|}{$\begin{array}{l}\text { Model I } \\
\text { Net Effects } \\
\end{array}$} & $\begin{array}{l}\text { Model II } \\
\text { Gross Effects }\end{array}$ \\
\hline & OR & $\mathrm{CI}$ & OR & $\mathrm{CI}$ & OR & $\overline{C I}$ & $\begin{array}{ll}\text { OR } & \text { CI }\end{array}$ \\
\hline \multicolumn{8}{|l|}{ Level of Stigma } \\
\hline Highly stigmatizing attitudes & 1.00 & & 1.00 & & 1.00 & & 1.00 \\
\hline Least stigmatizing & $2.13^{* *}$ & $(1.00-4.53)$ & $1.89 * *$ & $*(0.70-5.06)$ & $3.01 * *$ & $(1.14-7.94)$ & 4) $4.48^{* * *}(1.21-16.72)$ \\
\hline \multicolumn{8}{|l|}{ Age } \\
\hline $15-24$ & & & 1.00 & & & & 1.00 \\
\hline $25-34$ & & & $0.14 * * *$ & $*(0.03-0.55)$ & & & $5.48^{* * *}(1.64-18.39)$ \\
\hline $35+$ & & & 0.97 & $(0.25-3.73)$ & & & $3.53 * * \quad(1.09-11.46)$ \\
\hline \multicolumn{8}{|l|}{ Level of education } \\
\hline No/primary education & & & 1.00 & & & & 1.00 \\
\hline Secondary/higher education & & & $3.80^{* * *}$ & $(1.49-9.71)$ & & & $4.56 * * * *(1.97-10.56)$ \\
\hline \multicolumn{8}{|l|}{ Occupation } \\
\hline Formal sector & & & 1.00 & & & & 1.00 \\
\hline Informal sector & & & $5.29 * * *$ & $*(2.05-13.69)$ & & & $8.07 * * * *(3.62-17.99)$ \\
\hline \multicolumn{8}{|l|}{ Marital status } \\
\hline Never married & & & 1.00 & & & & 1.00 \\
\hline Ever married & & & $7.14 * * *$ & $(2.06-24.73)$ & & & $2.09 * *(0.74-6.0)$ \\
\hline \multicolumn{8}{|l|}{ Current sexual activity status } \\
\hline Sexually active & & & 1.00 & & & & 1.00 \\
\hline Not sexually active & & & 0.55 & $(0.06-4.86)$ & & & $1.92(0.27-13.67$ \\
\hline \multicolumn{8}{|l|}{ Ever used condoms } \\
\hline Yes ever used condoms & & & 1.00 & & & & 1.00 \\
\hline No never used condoms & & & $0.84^{* *}$ & $(0.24-2.83)$ & & & $0.49(0.22-1.11)$ \\
\hline
\end{tabular}




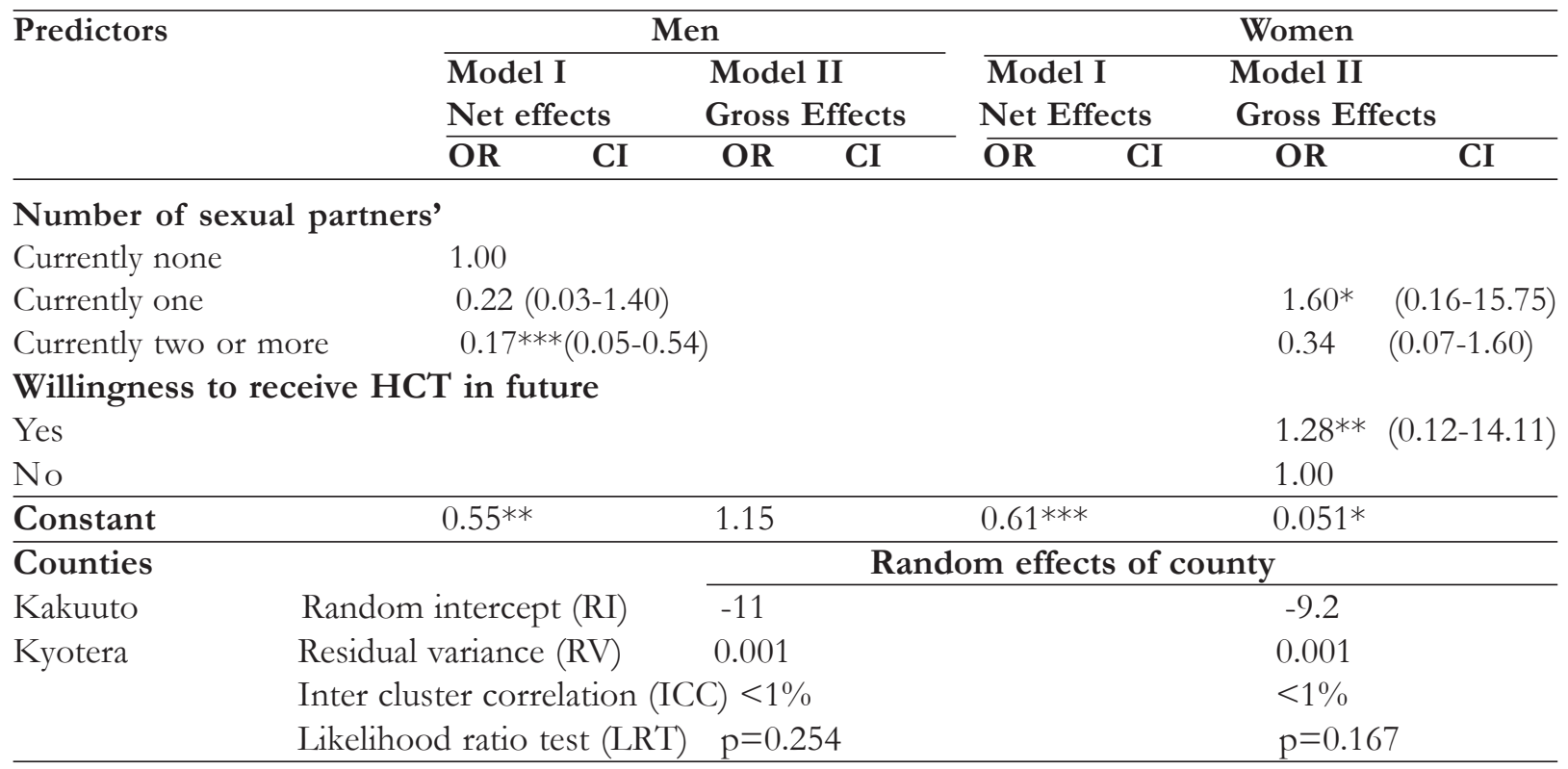

Level of significance $*<0.05 ; * *<0.01 ; * * *<0.001$; **** $<0.0001$

\section{Discussion}

HIV/AIDS continues to be a serious health problem in sub-Saharan Africa. Several interventions, including HCT are being implemented to prevent the further spread of the disease and treat those already infected. However, uptake of HCT is low in sub-Saharan Africa, which is partly attributed to HIV/AIDS stigma ${ }^{8,9}$. This study therefore assessed the level of stigma and examined its impact on uptake of HCT in a high HIV/AIDS prevalence population in Uganda.

Overall the study found that about $59 \%$ of men and women alike received HCT and $71.1 \%$ of men and $89.2 \%$ of women expressed least stigmatizing attitudes. Only $18.4 \%$ (12.2\% of men and $6.2 \%$ of women) expressed highly stigmatizing attitudes, indicating that the level of stigma is low in this study population. Uptake of HCT was also significantly higher among men and women who had least stigmatizing attitudes, which is consistent with previous studies in Uganda ${ }^{9}$ and Botswana in which stigmatizing attitudes were found to be low ${ }^{16}$. Having secondary/higher education, working in the informal sector, and being ever married were significant predictors of increased uptake of HCT. Uptake of HCT was significantly higher among women aged 25-34 years; 35 or more years old; and women with one sexual partner. Conversely, uptake of HCT was significantly less likely among men aged 25-34 years old and men who have never used condoms.

The higher uptake of HCT by men and women with secondary/higher education has been observed by previous studies ${ }^{17,18}$, which attributed it to better understanding of the importance of HCT in HIV prevention and AIDS treatment. Higher uptake of HCT by people in the informal sector in Rakai could be attributed to the Rakai Health Sciences project, which by early 2000 was already providing HIV/AIDS services including home based HCT in 56 mostly rural agricultural communities as part of its HIV epidemiological studies. A review of the Project's HIV counseling programme found a high uptake of HCT $(65 \%)$ in $2000^{19,20}$.

Increased uptake of HCT by ever married men and women, and women aged 25-49 years is expected because of the institutionalization of HCT as part of antenatal care, which has been observed by previous studies in Uganda, Ethiopia and Botswana ${ }^{21,22}$. This was attributed to the efforts to reduce the risk of HIV transmission from infected mothers to their babies. The higher uptake of HCT among currently married and previously married men and women may have also been a result of premarital HCT. Fear of knowing their HIV/AIDS positive status could prevent men who never used condoms, which is high risk behaviour to receive HCT. This is not encouraging as some of the men have multiple 
sexual partners. A previous study found that men who used condoms inconsistently were unlikely to receive HCT because of fear of positive test result ${ }^{23}$.

Unwillingness to take HCT by people engaging in multiple concurrent sexual relationships could be attributed to the already perceived HIV positive status. Conversely, the need for HCT could be dampened by polygamy, which is tolerated in Uganda, and is a risk of HIV transmission in the absence of HCT ${ }^{24}$. HCT should be encouraged in polygamous unions to reduce the risk of HIV transmission and people not in polygamous unions should be counseled to abandon multiple concurrent sexual partnerships. The observed willingness to receive HCT in future by women who previously received it is a good indicator of the importance of regular HCT in the prevention and treatment of HIV/AIDS. Previous studies found that people who received repeat HCT did so to ascertain previous negative test and repeat testers were more likely to adopt behaviours that reduce HIV transmission ${ }^{25}$. Repeat HCT is also necessary in all pregnancies and monitoring AIDS treatment.

\section{Limitations}

The measures used in this paper were self reported and therefore susceptible to social desirability biases. Generalizing the findings of this study is also limited by the small sample, restricting the study in a high prevalence population and a community epidemiological study area. The use of cross-sectional data also makes the temporality of stigma and other predictors of uptake of HCT in this study unknown. Nevertheless this study has contributed to previous studies on stigma and HCT by showing that HIV/ AIDS stigma is a significant predictor of HCT in high HIV prevalence populations.

\section{Conclusions}

The low level of HIV/AIDS stigma is associated with higher uptake of HCT. We also conclude that higher level of education, being ever married and a woman in reproductive ages and working in the informal sector are important predictors of HCT.

\section{Acknowledgements}

The authors would like to thank all those who participated in the study as respondents for sharing their HIV/AIDS stigma attitudes and its impact on uptake of HCT. We also extend our gratitude to the individuals who participated in the collection of the data used in this manuscript. Also appreciated are the reviewers for the constructive and positive comments made on the manuscript.

\section{References}

1. UNAIDS. AIDS Epidemic Updated. Geneva, 2008.

2. Ministry of Health (MOH) and ORC Macro. Uganda HIV/AIDS Sero-behavioural survey 2004-2005. Calverton, Maryland, USA: Ministry of Health and ORC Macro. 2006.

3. Uganda, Ministry of Health. HIV counselling and testing a national counsellor training Manual. Kampala, 2005.

4. Goffman, E: Stigma: Notes on the Management of Spoiled Identity. Prentice Hall. 1963.

5. Scambler G. Re-framing Stigma: Felt and Enacted Stigma and Challenges to the Sociology of Chronic and Disabling Conditions. Social Theory and Health 2004;2(1):29-46.

6. Earnshaw VA, Chaudoir SR. From conceptualizing to measuring HIV stigma: a review of HIV stigma mechanism measures. AIDS Behaviour 2009;13(6):1160-77.

7. Kalichman SC, Simbayi LC. Traditional beliefs about the causes of AIDS and AIDS related stigma in South Africa. AIDS Care 2004;16:57280.

8. Pharis A, Hoa NP, Tishelman C, Marrone G, Chuc NTK, Brugha R, et al. Community patterns of stigma towards persons living with HIV: A population based latent class analyses from rural Vietnam. BMC Public Health 2011;11:705 http:// www.biomedcentral.com/1471-2458/11/705.

9. Bwambale FB, Sarah NS, Byaruhanga S, Klyango JN, Karamagi CAS. Voluntary HIV counseling and testing among men in rural western Uganda: Implications for HIV prevention. BMC Public Health 2008;8:263.

10. Uganda Bureau of Statistics (UBOS). 2010 Statistical Abstract. UBOS, Kampala Uganda, 2010.

11. Government of Uganda. UNGASS Country Progress Report Uganda, January 2008December 2009, March 2010.

12. Sebudde S, Nangendo F. Voluntary counselling and testing services: breaking the resistance to access and utilization among the youths in Rakai district of Uganda. Educational research and review 2009;4(10):290-97. 
13. Nyblade, L, MacQuarrie K. Can We Measure HIV/AIDS-related Stigma and Discrimination?: Current knowledge about quantifying stigma in developing countries. Washington, D.C., USAID. 2006.

14. Genberg BL, Kawichai S, Chingano A, Senda $\mathrm{M}$, Chariyalerksak S, Konda KA, et al. Assessing HIV/AIDS stigma in developing countries. AIDS Behaviour 2008;12(5)772-80. Doi:10.1007/s10461007-9340-6.

15. Li B, Lingsma HF, Steyerberg EW, Lesaffre E. Logistic random effects regression models: a comparison of statistical packages for binary and ordinal outcomes. BMC Medical Research Method 2011;11:77

16. Letamo G. Prevalence of, and factors associated with, HIV/AIDS-related stigma and discriminatory attitudes in Botswana. Journal of Health Population and Nutrition 2003;21:347-56.

17. Young SD, Hlavka Z, Modiba P, Gray G, Rooyen HV, Richter L, et al. HIV-related Stigma, social norms, and HIV testing in Soweto and Vulindela, South Africa: National Institutes of Mental Health Project Accept (HPTN 043). Journal of Immune Deficiency syndrome 2010;55:620-24.

18. Divya R, Jody SH. The social determinants of HIV testing in Botswana: a keynote for addressing the epidemic. Health Economics and Financing Programme. Working paper 02/07. LSHTM 2007.

19. Matovu JKB, Kigozi G, Nalugoba F, WabwireMangen F, Gray RH. The Rakai project counseling programme experience. Tropical Medicine and International Health 2002;7(12):1064-67.
20. Mutale W, Michelo C, Jurgensen M, Fykesnes K. Home based voluntary counseling and testing found highly acceptable and reduces inequalities. BMC Public Health 2010;10(347):3-7.

21. Fabiani M, Ayella EO, Nattibi B. Factors influencing acceptance of VCT among Pregnant women in Northern Uganda. Antiretroviral Therapy 2003; (supp 1).

22. Abebaw D, Amare D, Mulumbert A. Determinants of acceptance of voluntary HIV testing among antenatal clinic attendees at Dil Chora Hospital, Dire Dawa, East Ethiopia. Ethiopian Journal of Health Development 2009;23(2)141-47.

23. Yaw DF. Male perspective(s) on condom use: Context of STI/HIV prevention in the University of Ghana community. Journal of Public Health and Epidemiology 2011;3(1):17-27.

24. Morris M, Kretzschmar M. Concurrent partnerships and the spread of HIV. AIDS 1997; 11 641-648.

25. Obare F, Fleming P, Anglewicz P, Thornton R, Martinson F, Kapatuka A, et al. Acceptance of repeat population-based voluntary counselling and testing for HIV in rural Malawi, Sexual Transmitted Infections 2009; 85(2):139-144.doi:10.1136/ sti.2008.030320. 